\title{
A randomized controlled trial protocol to test the efficacy of a dual-task multicomponent exercise program in the attenuation of frailty in long-term nursing home residents: Aging-ON $\mathrm{N}_{\text {DUAL-TASK }}$ study
}

Chloe Rezola-Pardo ${ }^{1}$, Haritz Arrieta' ${ }^{1}$ Susana Maria Gill', Jose Javier Yanguas ${ }^{2}$, Miren Iturburu ${ }^{3}$, Jon Irazusta ${ }^{1,4}$, Begoña Sanz ${ }^{1,4}$ and Ana Rodriguez-Larrad ${ }^{1 *}$ (I)

\begin{abstract}
Background: The purpose of the Aging-ON DUAL-TASK study is to determine if a supervised dual-task program carried out in long-term nursing homes is able to attenuate frailty in a greater extent than the same multicomponent exercise program alone.

Methods: This multicenter randomized controlled trial will include 188 participants who will be randomly allocated to either a multicomponent exercise program or to the same multicomponent program with simultaneous cognitive training (dual-task training). Inclusion criteria are as follows: $\geq 70$ years, $\geq 50$ on the Barthel Index, $\geq 20$ on the Mini Examen Cognoscitivo (MEC-35) who are able to stand up and walk independently for $10 \mathrm{~m}$. Subjects in the multicomponent group will attend a twice-a-week multicomponent exercise program of 1-h duration per session, consisting of strength and balance exercises. Participants in the dual-task group will perform the same multicomponent exercise program with concurrent individually tailored cognitive tasks. Study assessments will be conducted at baseline and at 3 months. The primary outcome measure will be gait speed under dual-task conditions and secondary outcomes will include physical fitness measurements, gait spatiotemporal parameters, cognition and emotional assessments, several frailty scales and objectively measured physical activity.

Discussion: The present research will add valuable information to the knowledge around the effects of the dual-task program in long-term nursing home residents, taking altogether physical, cognitive and emotional variables linked to frailty.
\end{abstract}

Trial registration: Australian and New Zealand Clinical Trials Registry (ANZCTR) with the identifier: ACTRN12618000536268. Registration date: 11/04/2018.

Keywords: Dual-task, Frailty, Exercise, Physical activity, Long-term nursing home, Cognitive frailty, Dual-task intervention, Older adults, Aging

\footnotetext{
* Correspondence: ana.rodriguez@ehu.eus

${ }^{1}$ Department of Physiology, Faculty of Medicine and Nursing, University of

the Basque Country (UPV/EHU), Barrio Sarriena s/n, E-48940 Leioa, Bizkaia,

Spain

Full list of author information is available at the end of the article
}

(c) The Author(s). 2019 Open Access This article is distributed under the terms of the Creative Commons Attribution 4.0 International License (http://creativecommons.org/licenses/by/4.0/), which permits unrestricted use, distribution, and 


\section{Introduction}

The global increase in life expectancy and consequent aging of the population, leads to estimates that the number of dependent older adults will rise from 350 million in 2010 to 488 million by 2030 [1]. Accordingly, the number of older adults living in long-term nursing homes will also increase considerably. Older adults in long-term nursing homes represent a complex and heterogeneous population with a high prevalence of dependence in the activities of daily living, cognitive impairment, depression, high fall rates, multimorbidity and polymedication $[2,3]$. In addition, long-term nursing home residents tend to be extremely inactive, engaging in sedentary activities for most of the day [4]. Thus, providing the best care for this population has become a challenge for both social and health care services [5].

In the last few years, research in aging has focused on frailty syndrome. Frailty is considered a state of vulnerability highly prevalent among the older adult population [6-8]. Although frailty has traditionally been described as a purely physical syndrome, a number of epidemiological studies have reported that frailty increases the risk of future cognitive decline and that cognitive impairment increases the risk of frailty, suggesting that physical frailty and cognitive impairment interact [9]. Cognition declines with age, with normal subtle cognitive changes that may affect everyday life functioning [10] and frail older adults usually perform worse in certain executive function and processing speed tests [11]. Recently, the International Academy on Nutrition and Aging (I.A.N.A) and the International Association of Gerontology and Geriatrics organized an International Consensus Group on "Cognitive Frailty", which proposed a definition of cognitive frailty [12] and suggested that all frail older adults should undertake a complete cognitive evaluation, including executive function tests [13].

In consonance with this idea, an impaired capacity to perform attention-demanding mobility activities such as carrying out two tasks (physical + cognitive) simultaneously, also known as dual-task, could be a novel marker of physical and cognitive frailty. Many activities of daily life involve the performance of several tasks at a time, creating competing demands for attentional resources that challenge both motor and cognitive functions [14]. Considering that attentional capacity is limited, when demands exceed capacity, performance of dual-tasks can be affected compared to performance of the same tasks in a single-task fashion. Indeed, older adults show greater impairments compared to their younger counterparts in cognitive-motor dual-task performance, such as naming animals while walking or making calculations during balance exercises $[15,16]$. Additionally, low dual-task performance capacity is associated with cognitive impairment and with a high risk of falling [17-19].
Previous studies of dual-task as a test of functional performance in older adults have focused on the gait speed test or on the Timed Up and Go test as physical tasks, while introducing semantic fluency or a calculus command as cognitive content. The difference between performance in the dual-task and the single-task tests is known as dual-task interference or dual-task cost [20]; this difference increases with aging [21]. The dual-task cost can be accounted for in both the physical and the cognitive domains. In this regard, the most commonly used formula is: dual-task cost $=(($ dual task - single task $)$ single-task) $\times 100 \%$ [18]. For the physical dual-task cost calculation, time in seconds is used, whereas for the cognitive dual-task cost, either the number of correct responses or the percent of correct responses can be used to compare between single and dual task performances.

Dual-task performance can be modified with specific dual-task training [22, 23]. In fact, this type of intervention can maintain or even improve cognitive function [24, 25], especially executive function [26]. Two models have been suggested that might explain training-mediated dualtask performance changes [27]. The task-automatization model is based on the assumption that individual tasks can be automatized and predicts similar improvements either with single-task or dual-task training [27]. Alternatively, the task-integration model advocates for the efficient integration of both tasks through dual-task training, resulting in dual-task performance improvements [27]. According to the latter model, dual-task performance would only improve after dual-task but not single-task training. Furthermore, dual-task training may be superior to single-task training [28-30], since dual-task training requires greater cognitive and motor resources and is more complex in terms of control and coordination demands. Pellecchia et al. [31] observed greater improvements in postural sway under dual-task conditions after dual-task training compared to singletask training, supporting the task-integration model and suggesting that both physical and cognitive functions interact in a way still to be revealed.

To our knowledge, no studies have explored the effects of a supervised dual-task multicomponent exercise intervention in long-term nursing home facilities from a broad perspective of frailty, assessing functional capacity under single-task and dual-task conditions, physical activity, cognitive performance and emotional status. Therefore, we designed a randomized multicenter study, the Aging-ON $\mathrm{N}_{\text {DUAL-TASK }}$ study, to test hypothesis that the addition of cognitive training to a supervised multicomponent exercise program can improve gait speed performance under dual-task conditions by, at least $0.08 \mathrm{~m} / \mathrm{seg}$ in a population of older adults in long-term nursing homes. The major aim of the Aging-ON $\mathrm{N}_{\text {DUAL-TASK }}$ study is to determine if a 
supervised dual-task program carried out in long-term nursing homes can attenuate frailty to a greater extent than the same multicomponent exercise program without cognitive training.

The Aging-ON $\mathrm{N}_{\text {DUAL-TASK }}$ study is based on a previous study $[32,33]$ in which feasibility regarding recruitment, adherence and safety of the multicomponent exercise program were successfully ascertained. A pilot study was performed to refine the outcome assessments, establish the progression of the cognitive training, and optimize the organizational infrastructure.

\section{Methods}

\section{Study design and participants}

Based on the proposed objective, an experimental multicentre simple randomized study was designed (Aging$\left.\mathrm{ON}_{\text {DUAL-TASK }}\right)$. Participants will be randomly allocated to either a multicomponent exercise program or to the same multicomponent program with simultaneous cognitive training (dual-task program). Participants will be recruited from eight long-term nursing homes in Gipuzkoa, Basque Country, Spain. Each site will enroll a minimum of 16 subjects and interventions will take place between June 2018 and December 2018. Researchers responsible for data gathering will be blinded to group assignment. The assessments will be carried out by research staff at baseline and at 3 months after the beginning of the intervention. The study has been designed and results will be reported following the CONSORT Statement extension for trials of non-pharmacological interventions and pragmatic intervention trials (Fig. 1).

\section{Inclusion and exclusion criteria, recruitment, and randomization}

The inclusion criteria, recruitment, and randomization methodologies in the Aging-ON $\mathrm{N}_{\text {DUAL-TASK }}$ study will be the same as on a previously published protocol [33]. The inclusion criteria will be: age $\geq 70$ years old; a Barthel Index [34] score $\geq 50$ and score $\geq 20$ on the MEC-35 Test [35] [Mini-examen cognoscitivo, an adapted and validated version of Mini Mental State Examination (MMSE) in Spanish]; and capacity to stand up and walk independently for at least $10 \mathrm{~m}$. Participants will not be eligible if they are judged clinically unstable by the medical staff, or have in any other condition in which entering the study would not be in the subject's best interests.

Identification of individuals that meet the inclusion criteria will be facilitated by the databases of the included long-term nursing homes. The primary recruitment strategy will be information provided to the

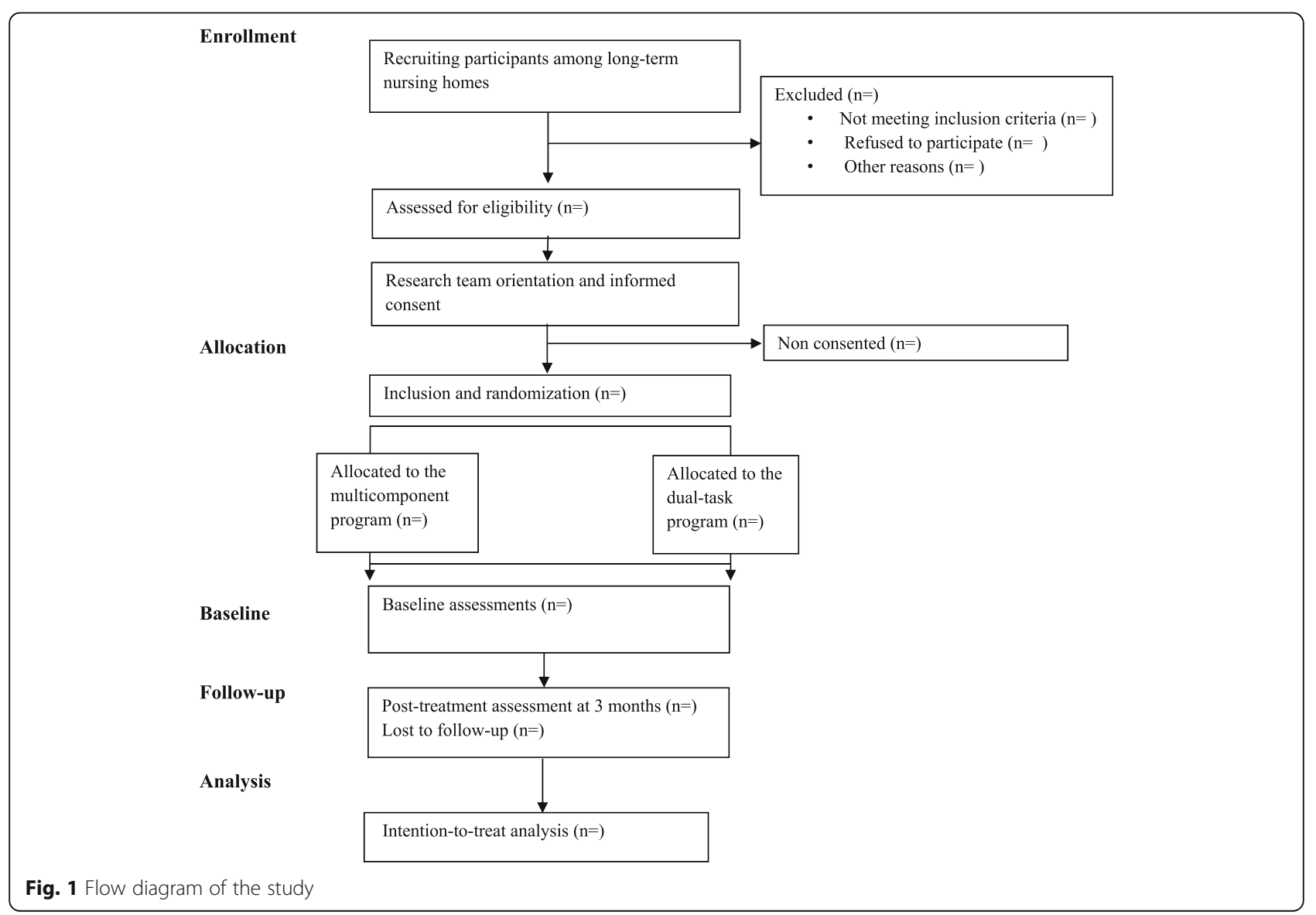


potential participants by the medical and nursing professionals from each facility. All volunteers will receive detailed study information at their reference sites through the research team: objectives, measurement variables, and other details about the interventions will be explained orally and in writing to both potential participants and their families. After signing the informed consent, the participants within each center will randomly be assigned (in a 1:1 ratio) through sealed opaque envelopes to either the multicomponent or the dual-task group by coin-tossing sequence generation.

\section{Multicomponent exercise program}

Feasibility and safety of the multicomponent exercise program were ascertained in a previous study which included full details on volume, intensity, and type of strength and balance exercises [32, 33]. Participants allocated to this group will attend a twice-a-week multicomponent exercise program of one-hour duration per session, consisting of strength and balance exercises conducted by an experienced physical trainer. Participants will also continue attending their usual activities and workshops.

\section{Dual-task program}

In the dual-task program, individually tailored cognitive tasks relying predominantly on executive function will be conducted concurrently with approximately four of the multicomponent exercises (Table 1).

The challenge of dual-task-s will be increased by augmenting the complexity of motor tasks (progressing from sitting to standing and from static to dynamic exercises, reducing base of support, etc) (Table 2) and/or cognitive tasks (number of stimuli, complexity of word categories, etc.) (Table 3).

The first week of the intervention will mainly serve to familiarize participants with the strength and balance exercises and adjust the level of difficulty of each cognitive function task to every participant in the group. In the second week, strength tests will be performed to individualize strength training and ensure training intensity. Throughout the following weeks, dual tasking will be applied mostly in strength exercises to train for divided attention allocation and will progressively move to balance exercises to optimize training adaptations and mimic everyday situations that require double tasking and increasing instability.

Cognitive training will be conducted based on six main cognitive functions essential for everyday life activities (Table 3). One of the most important functions to train is attention, which will be applied in form of: 1) divided attention tasks (with a secondary physical or cognitive task) where participants will have to divide their attention to ensure task achievement; 2) sustained attention
Table 1 Programation of the intervention for the 5th week

\begin{tabular}{|c|c|c|}
\hline Objective & Sesion 1 & Sesion 2 \\
\hline Warm-up 5 min & $\begin{array}{l}\text { Range of motion } \\
\text { for different joints }\end{array}$ & $\begin{array}{l}\text { Range of motion } \\
\text { for different joints }\end{array}$ \\
\hline \multirow[t]{7}{*}{ Strength training } & - & $\begin{array}{l}\text { Arm curl } 60 \% \\
2 \text { sets } 8-12 \text { rep } \\
+ \text { DAT }(c o g)\end{array}$ \\
\hline & $\begin{array}{l}\text { Chair stand } 60 \% \\
2 \text { sets } 8-12 \text { rep }\end{array}$ & $\begin{array}{l}\text { Chair stand } 60 \% \\
2 \text { sets } 8-12 \text { rep }\end{array}$ \\
\hline & $\begin{array}{l}\text { Leg flexion } 60 \% \\
2 \text { sets } 8-12 \text { rep } \\
+ \text { DAT }(\mathrm{cog})\end{array}$ & - \\
\hline & - & $\begin{array}{l}\text { Leg extension } 60 \% \\
2 \text { sets } 8-12 \text { rep } \\
+ \text { Inhibition task }\end{array}$ \\
\hline & $\begin{array}{l}\text { Leg abduction 60\% } \\
2 \text { sets } 8-12 \text { rep } \\
+ \text { Calculus task }\end{array}$ & - \\
\hline & - & $\begin{array}{l}\text { Hip extensión } 60 \% \\
2 \text { sets } 8-12 \text { rep }\end{array}$ \\
\hline & $\begin{array}{l}\text { Standing on tips } \\
\text { and heels } \\
3 \text { sets } 10 \text { rep } \\
+ \text { SAT }\end{array}$ & $\begin{array}{l}\text { Standing on tips } \\
\text { and heels } \\
3 \text { sets } 10 \text { rep } \\
+ \text { SAT }\end{array}$ \\
\hline \multirow[t]{6}{*}{ Balance training } & - & $\begin{array}{l}\text { Feet together stance } \\
2 \text { sets } 10 \mathrm{~s} \\
+ \text { DAT (physical) }\end{array}$ \\
\hline & $\begin{array}{l}\text { One legged stand } \\
2 \text { sets } 10 \mathrm{~s}\end{array}$ & - \\
\hline & $\begin{array}{l}\text { Semi-tandem/ } \\
\text { Tandem } \\
2 \text { sets } 10 \mathrm{~s} \\
+ \text { DAT (physical) }\end{array}$ & $\begin{array}{l}\text { Semi-tandem/ } \\
\text { Tandem } \\
2 \text { sets } 10 \mathrm{~s} \\
+ \text { DAT }(\mathrm{cog})\end{array}$ \\
\hline & $\begin{array}{l}\text { Circuit training } \\
2 \text { sets }\end{array}$ & - \\
\hline & - & $\begin{array}{l}\text { Stepping } 2 \\
\text { sets } 10 \text { rep }\end{array}$ \\
\hline & $\begin{array}{l}\text { Ball reaching } 2 \text { sets } \\
+ \text { Semantic memory }\end{array}$ & - \\
\hline Cool down 5 min & $\begin{array}{l}\text { Stretching, breathing, } \\
\text { relaxing exercises. }\end{array}$ & $\begin{array}{l}\text { Stretching, breathing } \\
\text { relaxing exercises. }\end{array}$ \\
\hline
\end{tabular}

rep repetitions, DAT divided attention task, $\operatorname{cog}$ cognitive, SAT sustained attention task

tasks, in which attention will have to be maintained throughout a certain time period (1-2 min); 3) shifting, where participants will have to shift their focus of attention between cognitive tasks. In addition, semantic fluency will consist of naming words according to different categories with increasing difficulty such as naming animals, professions or even dog breeds. Other executive functions including calculus or inhibitory control will also be trained, the latter consisting of overriding the natural response to certain stimuli. Finally, due to the fact that movement coordination, movement learning and sequencing are inherent to any exercise-based program, these will be present in both the multicomponent exercise program group and in dual-task group. 
Table 2 Detailed description of the general DT group intervention

\begin{tabular}{llll}
\hline 3 MONTHS & & & \\
\hline Objective & $\begin{array}{l}\text { 1ST MONTH } \\
\text { Familiarisation phase }\end{array}$ & $\begin{array}{l}\text { 2ND MONTH } \\
\text { Strength development } \\
\text { Static balance DT }\end{array}$ & $\begin{array}{l}\text { 3RD MONTH } \\
\text { Strength maintenance } \\
\text { Dynamic balance DT }\end{array}$ \\
\hline Strength & $3-4$ ex: 1-2 sets, 8-12 rep at 40-50\% of 1RM & $4-5$ ex: 2 sets, 8-12 rep at 60\% of 1RM & $4-5$ ex:1-2 sets, 8-12 rep at 65-70\% of 1RM \\
Balance & $\begin{array}{l}2-3 \text { ex, progressive difficulty in sitting } \\
\text { position and progressing to standing } \\
\text { position. }\end{array}$ & $\begin{array}{l}4-5 \text { ex, progressive difficulty in standing } \\
\text { position with decreasing arm support and } \\
\text { increasing instability. }\end{array}$ & $\begin{array}{l}\text { In 2-3 of strength ex and 1-2 } \\
\text { of balance ex }\end{array}$ \\
Dual-task & In 3-4 of strength ex & In 1-2 of strength ex and 3-4 of balance ex \\
& &
\end{tabular}

ex exercises, rep repetitions

\section{Outcome measures}

The primary outcome measure will be gait speed under dual-task conditions. The distance to be covered will be $9 \mathrm{~m}$ on a smooth non-slippery surface with starting and ending points marked on the floor with tape. The cognitive task to be performed will previously be explained to participants. Straight after the explanation, the participant will be asked to walk at a comfortable pace on a straight line while simultaneously performing the cognitive task. Time to perform the test will be measured following the procedure described by Bohannon [36]. Gait speed will be then calculated dividing the covered distance (in meters) by the employed time (in seconds).

In addition, both gait spatiotemporal parameters (cadence, single and double support time, etc.) and cognition

Table 3 Progression of complexity of secondary tasks by levels of difficulty

\begin{tabular}{|c|c|c|c|c|c|c|}
\hline \multicolumn{2}{|c|}{ Main cognitive function } & \multirow[b]{2}{*}{$\begin{array}{l}\text { Level } 1 \\
\text { The participant } \\
\text { will repeat a } \\
\text { specific word } \\
\text { from a certain } \\
\text { category (e.g } \\
\text { house) every } \\
\text { time the } \\
\text { instructor says it }\end{array}$} & \multirow[b]{2}{*}{$\begin{array}{l}\text { Level } 2 \\
\text { The participant will } \\
\text { raise a hand every } \\
\text { time the instructor } \\
\text { says a specific word } \\
\text { from a certain } \\
\text { category or when } \\
\text { a green card is } \\
\text { presented }\end{array}$} & \multirow[b]{2}{*}{$\begin{array}{l}\text { Level } 3 \\
\text { The participant will } \\
\text { raise a hand every } \\
\text { time the instructor } \\
\text { says two specific } \\
\text { words from certain } \\
\text { categories or when } \\
\text { a green card is } \\
\text { presented }\end{array}$} & \multirow[b]{2}{*}{$\begin{array}{l}\text { Level } 4 \\
\text { The participant will } \\
\text { raise a hand every } \\
\text { time the instructor } \\
\text { says two specific } \\
\text { words from certain } \\
\text { categories or when } \\
\text { a green card is } \\
\text { presented or when } \\
\text { the instructor claps }\end{array}$} & \multirow[b]{2}{*}{$\begin{array}{l}\text { Level } 5 \\
\text { The participant will } \\
\text { raise a hand and repeat } \\
\text { the word every time } \\
\text { the instructor says two } \\
\text { specific words from } \\
\text { certain categories or } \\
\text { when a green card is } \\
\text { presented or when } \\
\text { the instructor claps }\end{array}$} \\
\hline Attention & $\begin{array}{l}\text { Divided (cognitive) } \\
\text { CATEGORIES:Buildings/ } \\
\text { Dairy products/ colors }\end{array}$ & & & & & \\
\hline & Divided (physical) & \multicolumn{5}{|c|}{$\begin{array}{l}\text { Participants will carry out the physical task whilst maintaining a cup with a ball upright to avoid the ball from } \\
\text { falling }\end{array}$} \\
\hline & Sustained & $\begin{array}{l}\text { Naming months } \\
\text { of the year } \\
\text { forward }\end{array}$ & $\begin{array}{l}\text { Naming months } \\
\text { of the year forward } \\
\text { starting from a } \\
\text { random month }\end{array}$ & $\begin{array}{l}\text { Naming even or odd } \\
\text { months of the year } \\
\text { forward }\end{array}$ & $\begin{array}{l}\text { Naming months of } \\
\text { the year backwards }\end{array}$ & $\begin{array}{l}\text { Naming months of the } \\
\text { year backwards starting } \\
\text { from a random month }\end{array}$ \\
\hline & Shifting & \multicolumn{5}{|c|}{ Participants will be asked to shift focus from a cognitive task to another on some of the dual tasks } \\
\hline \multicolumn{2}{|c|}{ Semantic fluency } & $\begin{array}{l}\text { Naming colors/ } \\
\text { days of the } \\
\text { week/names }\end{array}$ & $\begin{array}{l}\text { Naming members } \\
\text { of the family/clothes }\end{array}$ & Naming professions & $\begin{array}{l}\text { Naming cooking } \\
\text { instruments or general } \\
\text { tools }\end{array}$ & $\begin{array}{l}\text { Naming fish, dog } \\
\text { or tree types }\end{array}$ \\
\hline \multicolumn{2}{|l|}{ Inhibition } & $\begin{array}{l}\text { If the instructor } \\
\text { says YES they } \\
\text { respond NO } \\
\text { and viceversa }\end{array}$ & $\begin{array}{l}\text { Every time the } \\
\text { instructor says HEADS } \\
\text { they have to answer } \\
\text { TAILS and viceversa } \\
\text { and Previous entry }\end{array}$ & $\begin{array}{l}\text { If a green card is } \\
\text { presented they have } \\
\text { to say RED and } \\
\text { when a red card is } \\
\text { presented they have } \\
\text { to say GREEN }\end{array}$ & $\begin{array}{l}\text { Level } 2 \text { and level } 3 \\
\text { instructions altogether }\end{array}$ & $\begin{array}{l}\text { If the word RED is } \\
\text { presented in a green } \\
\text { color they have to } \\
\text { say GREEN and vice } \\
\text { versa and when the } \\
\text { word YES in red } \\
\text { color or NO in green } \\
\text { color, they have to } \\
\text { name the color. }\end{array}$ \\
\hline \multicolumn{2}{|c|}{ Problem solving (calculus) } & $\begin{array}{l}\text { Counting by twos } \\
\text { starting from a } \\
\text { number } \geq 30\end{array}$ & $\begin{array}{l}\text { Counting by threes } \\
\text { from a number } \geq 50\end{array}$ & $\begin{array}{l}\text { Substracting by twos } \\
\text { from a number } \geq 30\end{array}$ & $\begin{array}{l}\text { Substracting by threes } \\
\text { from a number } \geq 50\end{array}$ & $\begin{array}{l}\text { Substracting by fours } \\
\text { from a number } \geq 100\end{array}$ \\
\hline \multicolumn{2}{|c|}{ Movement coordination } & \multirow{2}{*}{\multicolumn{5}{|c|}{$\begin{array}{l}\text { Inherent to the } \\
\text { muticomponent } \\
\text { exercise program }\end{array}$}} \\
\hline $\begin{array}{l}\text { Movemen } \\
\text { sequencir }\end{array}$ & $\begin{array}{l}\text { t learning and } \\
g\end{array}$ & & & & & \\
\hline
\end{tabular}


(number of correct, incorrect and total responses) will be analyzed, and compared with performance in the single-task modality. This difference is referred to as dual-task cost, and will be calculated using the formula: $(($ dual task - single-task)/single-task $\times 100)$ [18].

Secondary outcome measures will include functional (Table 4), cognitive, and emotional assessments (Table 5). Functional capacity will be determined by the following tests (Table 4): the Short Physical Performance Battery test [37] (SPPB); the Senior Fitness Test [38] (SFT); the instrumented Timed Up and Go test [39] (iTUG; BTS Biomedical G-WALK triaxial accelerometer and gyroscope); usual walking speed [36]; the handgrip strength test [40] (Jamar dynamometer) and Berg balance test [41]. Frailty assessment will include the Tilburg Frailty index [42], the Frailty index [43] and the Rockwood clinical frailty scale [44]. In addition, participants will wear an accelerometer (Actigraph GT3X model (Actigraph LLC, Pensacola, FL, USA)) on the hip with a belt for 7 days to measure active and sedentary periods during everyday life, by daily step quantification. Active-period intensities will be classified as light, moderate or vigorous based on Freedson and colleagues' criteria [45] and recorded in minutes.

For cognitive and emotional assessment (Table 5), participants will be assessed through the Montreal Cognitive Assessment [46] (MoCA), the Coding and Symbol Search test (which provide a measure of processing speed) from the Wechsler Adult Intelligence Scale, Fourth Edition (WAIS-IV) [47], the Trail Making Test part A [48] (TMT), the Rey Auditory Verbal Learning Test [49] (RAVLT), the Anxiety and Depression Goldberg Scale [50], the Jong Gierveld loneliness scale [51], and the Quality of Life Alzheimer's disease scale [52] (QoL-AD).
The following additional variables will also be registered: sociodemographic variables: age, gender, socioeconomic situation, educational level, and marital status; level of independence in activities of daily living: Barthel index [34]; cognitive impairment assessed through MEC35 [35]; anthropometric measurements: weight, height, body mass index, waist and hip circumferences, and waist-to-hip ratio; and clinical outcomes Charlson comorbidity index [53], number of falls, visits to the emergency service, number and length of hospitalizations, death rates, and medication.

\section{Dual-task assessment}

The secondary tasks included in the dual-task evaluation will be of three different natures: 1) semantic fluency: naming animals or fruits and vegetables; 2) backward counting by ones; and 3) inhibition ability through the Go no go test (when the evaluator says 'one', the participant has to respond 'two' and viceversa). We selected these tasks by the following process: a) a review of the literature, b) expert consultation through interviews and a discussion group, c) final selection.

Cognitive tasks will be applied during two different physical function tests: $9 \mathrm{~m}$ usual gait speed and the Timed Up and Go test. In addition, these physical tasks will be performed in a single task mode to allow for dual-task cost calculation. Dual-task gait speed and dual-task Timed Up and Go tests will be performed on two non-consecutive testing days to minimize learning effects and the order of the dual-task and the single-task will be randomized for the same purpose. In addition, participants will wear an accelerometer (BTS Biomedical G-WALK triaxial accelerometer and gyroscope) during

Table 4 Functional assessment tests

\begin{tabular}{|c|c|c|}
\hline Test (Reference) & Functions/Parameters & Description \\
\hline $\begin{array}{l}\text { Short Physical Performance Battery (SPPB) } \\
\text { (Guralnik et al., 1994) }^{a}\end{array}$ & $\begin{array}{l}\text { Lower extremity function: static balance, } \\
\text { gait speed and getting in and out of } \\
\text { a chair }\end{array}$ & $\begin{array}{l}\text { Side-by-side, semi-tandem and tandem stands }(10 \mathrm{~s}) ; 4 \mathrm{~m} \text { walk } \\
\text { test at comfortable speed and } 5 \text { quickly sit to stand from a } \\
\text { chair without upper extremity assistance }\end{array}$ \\
\hline Senior Fitness Test (Rikli \& Jones, 2007) ${ }^{a}$ & $\begin{array}{l}\text { Upper and lower extremity strength and } \\
\text { flexibility, static and dynamic balance } \\
\text { and aerobic capacity }\end{array}$ & $\begin{array}{l}\text { Chair-stands in } 30 \text { s; } 6 \text {-min walking test; arm curl test (30 s); chair } \\
\text { sit and reach; back scratch and } 8 \text { Foot Up and Go test }\end{array}$ \\
\hline $\begin{array}{l}\text { Instrumented Timed Up and Go test } \\
\text { (BTS Biomedical G-WALK) } \\
\text { (Mathias et al., 1986) }^{\mathrm{a}}\end{array}$ & Dynamic balance & $\begin{array}{l}\text { Get up from a chair, walk } 3 \text { m at a normal pace, turn and walk } \\
\text { back to sit down again }\end{array}$ \\
\hline $\begin{array}{l}\text { Instrumented walking speed (BTS } \\
\text { Biomedical G-WALK) } \\
\text { (Bohannon et al., 1996) }^{\text {a }}\end{array}$ & $\begin{array}{l}\text { Standard gait parameters: speed, step } \\
\text { frequency, cadence }\end{array}$ & Walk for 4 and $9 \mathrm{~m}$ at comfortable speed \\
\hline $\begin{array}{l}\text { Bilateral handgrip strength test } \\
\text { (Jamar dynamometer) (Fess, 1992) }^{\text {a }}\end{array}$ & Hand grip strength & $\begin{array}{l}\text { Squeeze the dynamometer with maximum isometric effort for } \\
\text { about } 5 \mathrm{~s}\end{array}$ \\
\hline Berg balance test (Berg et al., 1992)a & Postural stability & Performance of 14 functional tasks \\
\hline $\begin{array}{l}\text { Accelerometry [Actigraph GT3X model } \\
\text { (Actigraph LLC, Pensacola, FL, USA)] } \\
\text { (Freedson et al., 1988) }^{\text {a }}\end{array}$ & $\begin{array}{l}\text { Active and sedentary periods during } \\
\text { everyday life }\end{array}$ & $\begin{array}{l}7 \text { days period quantification of the number of steps performed } \\
\text { per day and minutes completed at light, moderate or vigorous } \\
\text { intensity }\end{array}$ \\
\hline
\end{tabular}

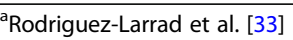


Table 5 Cognitive and Emotional assessment tests

\begin{tabular}{|c|c|c|}
\hline Test (Reference) & Functions & Description \\
\hline $\begin{array}{l}\text { Montreal Cognitive Assessment } \\
\text { (MoCA) (Coen et al., 2016) }\end{array}$ & $\begin{array}{l}\text { Mild Cognitive Impairment, } \\
\text { Early Alzheimer's disease }\end{array}$ & $\begin{array}{l}\text { Covered domains: attention and concentration, executive functions, memory, } \\
\text { language, visuoconstructional skills, conceptual thinking, calculations, orientation }\end{array}$ \\
\hline $\begin{array}{l}\text { Wechsler Adult Intelligence Scale } \\
\text { (WAIS-IV) (Wechsler et al., 2010) }\end{array}$ & Cognitive impairment & Covered domains: attention, visual scanning, motor speed \\
\hline $\begin{array}{l}\text { Trail Making Test (TMT) } \\
\text { (Reitan, 1958) }\end{array}$ & Cognitive impairment & $\begin{array}{l}\text { Assesses: visual-conceptual and visual-motor tracking, sustained attention and task } \\
\text { alternation abilities }\end{array}$ \\
\hline $\begin{array}{l}\text { Rey Auditory Verbal Learning Test } \\
\text { (RAVLT) (Lezak, 1995) }\end{array}$ & $\begin{array}{l}\text { Memory and learning } \\
\text { capacity }\end{array}$ & $\begin{array}{l}\text { Evaluates short- and long-term verbal memory assessing the ability to learn a list } \\
\text { of } 15 \text { common words }\end{array}$ \\
\hline $\begin{array}{l}\text { Anxiety and Depression Goldberg } \\
\text { Scale (Goldberg et al., 1988) }\end{array}$ & Affective state & Includes nine depression and nine anxiety items from the past month \\
\hline $\begin{array}{l}\text { The Jong Gierveld loneliness scale } \\
\text { (de Jong-Gierveld, 1987) }\end{array}$ & $\begin{array}{l}\text { Emotional and social } \\
\text { loneliness }\end{array}$ & $\begin{array}{l}\text { Includes characteristics of the social network, background variables, personality } \\
\text { characteristics, and evaluative aspects }\end{array}$ \\
\hline $\begin{array}{l}\text { Questionnaire QoL-AD } \\
\text { (Logsdon et al., 2002) }\end{array}$ & Perceived quality of life & Self-rated quality of life for people with cognitive impairments \\
\hline
\end{tabular}

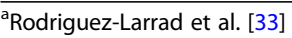

the tests to measure gait kinematic parameters such as step number, cadence, step symmetry, and step time variability. The number of total responses, errors, repetitions, and stops will be recorded. No instructions will be given regarding task prioritization.

\section{Safety assessments}

All co-existing diseases or conditions related to the intervention will be treated in accordance with prevailing medical practice and will be reported as an adverse event. In cases where the functional and cognitive state of a participant decreases due to an adverse event (e.g. illness, falls, etc.) the program will be individualized and adapted for that person upon her/his return.

\section{Power and sample size}

Sample size for the current study was calculated to detect a significant clinical difference on the dual-task gait speed test [54]. Accepting an alpha risk of 0.05 and a beta risk of 0.20 in a bilateral contrast, 141 individuals are required to detect a difference equal to or greater than $0.08 \mathrm{~m} / \mathrm{seg}$ in the dual-task gait speed test $(\mathrm{SD}=$ 0.24 ). The sample size was increased by $20 \%$ to account for losses during follow-up and an additional 5\% for mortality. The resulting sample size is 188 individuals, allocating 94 participants to each group.

\section{Statistical considerations}

Data analysis will be performed using the IBM SPSS Statistics 24 statistical software package (SPSS, Inc., Chicago, IL). Intention-to-treat analyses will be performed and the level of statistical significance will be set at $p<.05$ for all computations. First, all data will be checked for normality of distribution using the Kolmogorov-Smirnov test. Results will be expressed as mean (with standard deviation) for continuous and normally distributed variables and as median (with interquartile range) when normality of data for that variable cannot be assumed. In the case of categorical variables, frequency counts and percentages will be used to describe the results. Tests for baseline comparisons will be selected based on the nature and distribution of the data: Student's-t test with continuous and normally distributed variables, Mann-Whitney test with non-normally distributed continuous variables, and Chi-squared test with categorical variables.

To test the effects of training interventions, mixed-designed ANCOVA-s or the Friedman test, including baseline measurements, age, or gender as covariates, will be performed for physical, cognitive, and emotional variables. In cases where a significant $F$ value is found, LSD post hoc procedures will be performed for pairwise comparisons.

\section{Discussion}

The current trial is a large multi-center randomized study aiming to investigate whether dual-task performance, including gait and cognitive parameters, can be improved by specific dual-task training. So far, guidelines for the geriatric population and professionals working in the field are scarce, despite the exponentially increasing number of people above 65 years old. Older adults in long-term nursing homes are at particular risk of adverse outcomes and have been the focus of interventions aiming to prevent or reverse frailty [55].

The results of the present study will add valuable knowledge about the effects of the dual-task program in long-term nursing home residents, taking together functional, cognitive, and emotional variables linked to frailty. Particularly, analysis of a multicomponent exercise program and the same program with simultaneous cognitive training, or dual-task, will help us to design 
interventions to improve or at least maintain functionality and cognition in long-term nursing home residents.

One of our main concerns at the time of designing the dual-task intervention was the fact that when performing a dual-task exercise, the execution velocity of the physical task could be reduced when compared with a single task exercise. In addition, movement technique could also be altered if compared to single task training. Consequently, we feared that a dual-task program might affect physical performance and hence not improve physical parameters to the same extent as the multicomponent program. Thus, we conducted a pilot study to ascertain if both the multicomponent and the dual-task programs produce similar training adaptations, in which we successfully observed significant physical improvements in both groups [56].

Methodological strengths of the present study include the fact that the dual-task program here is based on a previously published physical exercise protocol. This protocol was feasible and demonstrated improvements in many functional outcomes [32,33]. In addition, the proposed interventions are easy to deliver and include exhaustive practical information regarding implementation such as training frequency, volume, intensity, individualization, and resting periods. This will allow an easy and straightforward implementation in long-term nursing homes. The existing literature about exercise protocols for older adults living in long-term care facilities includes few randomized controlled trials and the methodology tends to be heterogeneous. Furthermore, description of the methods used is often not enough to allow for replication.

We also recognize possible limitations to the study. The selected inclusion criteria preclude the majority of long-term nursing home residents, as we will include light to moderately dependent subjects while the prevalent profile in this type of institution is severely dependent. Consequently, we might encounter difficulties reaching the desired sample size. However, the large number of agreements made with long-term care institutions will facilitate the recruitment of enough subjects.

The proposed interventions will help to define the best approach to prevent the functional, cognitive, and emotional decline associated with age in older adults living in long-term nursing homes, considering feasibility and adherence.

\begin{abstract}
Abbreviations
I.A.N.A: International Academy on Nutrition and Aging; iTUG: instrumented Timed Up and Go test; MEC-35: Mini Examen Cognoscitivo; MMSE: Mini Mental State Examination; MoCA: Montreal Cognitive Assessment; QoLAD: Quality of Life Alzheimer's disease scale; RAVLT: Rey Auditory Verbal Learning Test; SFT: Senior Fitness Test; SPPB: Short Physical Performance Battery test; TMT: Trail Making Test; WAIS-IV: Wechsler Adult Intelligence Scale, Fourth Edition
\end{abstract}

\section{Acknowledgements}

We would like to thank all the forthcoming participants and their families for their cooperation and their confidence in the research team. The authors also would like to express their gratitude to all the nursing home staff for their time and assistance during the coming fieldwork process: the Bermingham, Lamourous, Julián Rezola (Matia), Anaka (Caser), Betharram (Caser), Zorroaga, Villa Sacramento (DomusVi), Berra (DomusVi), and San Markosene long-term nursing homes.

\section{Funding}

This research is supported by a research grant from the Basque Government (RIS3 316/07; ELKARTEK17/61; №. EXPT.: KK-2017/00085; "Etorkizuna Erakiz"). This research was partially supported by the University of the Basque Country (UPV/EHU) (PPG17/34) and the Basque Government (IT922-16). Chloe Rezola and Haritz Arrieta are supported by two fellowships from University of the Basque Country (UPV/EHU).

\section{Availability of data and materials}

'Not applicable'.

\section{Authors' contributions}

SMG, JI, ARL and JJY conceived and designed the experiments; CR and HA performed the experiments; $C R$ and $A R L$ analyzed and interpreted the data; $\mathrm{Ml}$ contributed the recruitment of the participants; CR, ARL, SMG, JI and MI wrote the paper. All authors read and approved the final manuscript.

\section{Ethics approval and consent to participate}

The study has been approved by the Committee on Ethics in Research of the University of the Basque Country (Humans Committee Code M10/ 2016/105). All participants will provide written informed consent based on documents approved by the University of the Basque Country Institutional Review Board. In addition, the study will be conducted in accordance with Good Clinical Practice, applicable local regulatory requirements, and the guiding principles of the Declaration of Helsinki.

Consent for publication

'Not applicable'.

\section{Competing interests}

The authors declare that they have no competing interests.

\section{Publisher's Note}

Springer Nature remains neutral with regard to jurisdictional claims in published maps and institutional affiliations.

\section{Author details}

${ }^{1}$ Department of Physiology, Faculty of Medicine and Nursing, University of the Basque Country (UPV/EHU), Barrio Sarriena s/n, E-48940 Leioa, Bizkaia, Spain. 'Fundación Bancaria "La Caixa", Plaça Weyler, 3, 07001 Palma, Illes Balears, Spain. ${ }^{3}$ Matia Instituto, Camino de los Pinos 35, E-20018 Donostia-San Sebastian, Gipuzkoa, Spain. ${ }^{4}$ BioCruces Health Research Institute, Plaza de Cruces, 48903 Barakaldo, Bizkaia, Spain.

Received: 23 July 2018 Accepted: 19 December 2018

Published online: 08 January 2019

\section{References}

1. Prince $M$, Prina M, Guerchet M. Journey of caring, an analysis of longterm Care for Dementia. World Alzheimer report 2013. London: Alzheimer's Disease International; 2013. http://www.alz.co.uk/research/ WorldAlzheimerReport2013.pdf

2. De Souto BP, Morley JE, Chodzko-Zajko W, et al. Recommendations on physical activity and exercise for older adults living in long-term care facilities: a taskforce report. J Am Med Dir Assoc. 2016;17(5):381-92.

3. Bercovitz A, Dwyer LL, Jones A, et al. The National Nursing Home Survey 2009; 2004 overview. Vital Health Stat. 2009;13(167):1-155.

4. Bates-Jensen BM, Alessi CA, Cadogan M, et al. The minimum data set bedfast quality indicator: differences among nursing homes. Nurs Res. 2004;53(4):260-72.

5. Pereira C, Rosado H, Cruz-Ferreira A, et al. Effects of a 10-week multimodal exercise program on physical and cognitive function of nursing home residents: a psychomotor intervention pilot study. Aging Clin Exp Res. 2017. https://doi.org/10.1007/s40520-017-0803-y. 
6. Rodriguez-Manas L, Fried LP. Frailty in the clinical scenario. Lancet. 2015; 385(9968):e7-9.

7. Collard RM, Boter H, Schoevers RA, et al. Prevalence of frailty in communitydwelling older persons: a systematic review. J Am Geriatr Soc. 2012;60(8): 1487-92.

8. Santos-Eggimann B, Cuénoud P, Spagnoli J, et al. Prevalence of frailty in middle-aged and older community-dwelling Europeans living in 10 countries. J Gerontol A Biol Sci Med Sci. 2009;64(6):675-81.

9. Robertson DA, Savva GM, Kenny RA. Frailty and cognitive impairment-a review of the evidence and causal mechanisms. Ageing Res Rev. 2013;12(4):840-51.

10. Harada CN, Love MC, Triebel K. Normal cognitive aging. Clin Geriatr Med. 2013;29(4):737.

11. Langlois F, Vu TT, Kergoat MJ, et al. The multiple dimensions of frailty: physical capacity, cognition, and quality of life. Int Psychogeriatr. 2012;24(9):1429-36

12. Kelaiditi E, Cesari M, Canevelli M, et al. Cognitive frailty: rational and definition from an (I.a.N.a./l.a.G.G.) international consensus group. J Nutr Health Aging. 2013;17(9):726-34.

13. Martínez-Ramírez A, Martinikorena I, Lecumberri P, et al. Dual task gait performance in frail individuals with and without mild cognitive impairment. Dement Geriatr Cogn Dis. 2016;42(1-2):7-16.

14. Plummer P, Zukowski LA, Giuliani C, et al. Effects of physical exercise interventions on gait-related dual-task interference in older adults: a systematic review and meta-analysis. Gerontology. 2015;62(1):94-117.

15. Wickens CD. Multiple resource and performance prediction. Theor Issues Ergon Sci. 2002;3:159-77.

16. Albinet $C$, Bernard PL, Palut Y. Attentional control of postural stability in institutionalised elderly people: effects of a physical exercise program. Ann Readapt Med Phys. 2006;49:625-31.

17. Beauchet $\mathrm{O}$, Annweiler $C$, Dubost $V$, et al. Stops walking when talking: a predictor of falls in older adults? Eur J Neurol. 2009;16:786-95.

18. Plummer-D'Amato P, Brancato B, Dantowitz M, et al. Effects of gait and cognitive task difficulty on cognitive-motor interference in aging. J Aging Res. 2012. https://doi.org/10.1155/2012/583894.

19. Faulkner KA, Redfern MS, Cauley JA, et al. Multitasking: association between poorer performance and a history of recurrent falls. JAGS. 2007;55:570-6.

20. Yogev-Seligmann G, Hausdorff JM, Giladi N. The role of executive function and attention in gait. Mov Disord. 2008;23:329-42.

21. Al-Yahya E, Dawes H, Smith L, et al. Cognitive motor interference while walking: a systematic review and meta-analysis. Neurosci Biobehav Rev. 2011;35:715-28

22. Falbo S, Condello G, Capranica $L$, et al. Effects of physical-cognitive dual task training on executive function and gait performance in older adults: a randomized controlled trial. Biomed Res Int. 2016. https://doi.org/10.1155/ 2016/5812092

23. Halvarsson A, Franzen E, Stahle A. Balance training with multi-task exercises improves fall-related self-efficacy, gait, balance performance and physical function in older adults with osteoporosis: a randomized controlled trial. Clin Rehabil. 2015;29(4):365-75.

24. Langdon KD, Corbett D. Improved working memory following nove combinations of physical and cognitive activity. Neurorehabil Neural Repair. 2012:26:523-32.

25. Schaefer S, Schumacher $\mathrm{V}$. The interplay between cognitive and motor functioning in healthy older adults: findings from dual-task studies and suggestions for intervention. Gerontology. 2011;57(3):239-46.

26. Prakash RS, Voss MW, Erickson Kl, et al. Physical activity and cognitive vitality. Annu Rev Psychol. 2015;66(1):769-97.

27. Silsupadol P, Siu KC, Shumway-Cook A, et al. Training of balance under single- and dual-task conditions in older adults with balance impairment. Phys Ther. 2006;86(2):269-81.

28. Silsupadol P, Shumway-Cook A, Lugade V, et al. Effects of single-task versus dual-task training on balance in older adults: a double-blind, randomized controlled trial. Arch Phys Med Rehabil. 2009;90:381-7.

29. Silsupadol P, Lugade V, Shumway-Cook A, et al. Training-related changes in dual-task walking performance of elderly persons with balance impairment: a double-blind, randomized controlled trial. Gait Posture. 2009;29:634-9.

30. Wollesen B, Voelcker-Rehage C. Training effects on motor-cognitive dualtask performance in older adults. Eur Rev Aging Phys Act. 2013;11(1):5.

31. Pellecchia GL. Dual-task training reduces impact of cognitive task on postural sway. J Mot Behav. 2005;37(3):239-46.
32. Arrieta H, Rezola-Pardo C, Zarrazquin I, et al. A multicomponent exercise program improves physical function in long-term nursing home residents: a randomized controlled trial. Exp Gerontol. 2018;8(103):94-100.

33. Rodriguez-Larrad A, Arrieta H, Rezola C, et al. Effectiveness of a multicomponent exercise program in the attenuation of frailty in long-term nursing home residents: study protocol for a randomized clinical controlled trial. BMC Geriatrics. 2017;17(1):60.

34. Wade DT, Collin C. The Barthel ADL Index: a standard measure of physical disability? Int Disabil Stud. 1988;10(2):64-7.

35. Lobo A, Saz P, Marcos G, et al. Revalidación y normalización del MiniExamen Cognoscitivo (primera versión en castellano del Mini-Mental Status Examination) en la población general geriátrica. Med Clin (Barc). 1999; 112(20):767-74

36. Bohannon RW, Andrews AW, Thomas MW. Walking speed: reference values and correlates for older adults. J Orthop Sports Phys Ther. 1996;24(2):86-90.

37. Guralnik JM, Simonsick EM, Ferrucci L, et al. A short physical performance battery assessing lower extremity function: association with self-reported disability and prediction of mortality and nursing home admission. J Gerontol. 1994:49(2):M85-94.

38. Rikli RE, Jones CJ. Senior fitness test. Champaign: Human Kinetics; 2001. ISBN 0-7360-3356-3364

39. Mathias S, Nayak US, Isaacs B. Balance in elderly patients: the "get-up and go" test. Arch Phys Med Rehabil. 1986;67(6):387-9.

40. Fess EE. Grip strength. In: Casanova JS, editor. Clinical assessment recommendations, $2^{\text {nd }}$ ed. Chicago: American Society of Hand Therapists; 1992. p. 41-5.

41. Berg KO, Wood-Dauphinée SL, Williams II, et al. Measuring balance in the elderly: validation of an instrument. Can J Publ Health. 1992;83:57-11.

42. Gobbens RJ, van Assen MA, Luijkx KG, et al. The Tilburg frailty Indicator: psychometric properties. J Am Med Dir Assoc. 2010;11(5):344-55.

43. Fried $L P$, Tangen $C M$, Walston J, et al. Frailty in older adults: evidence for a phenotype. J Gerontol A Biol Sci Med Sci. 2001;56(3):M146-56.

44. Rockwood K, Song X, Macknight C, et al. A global clinical measure of fitness and frailty in elderly people. CMAJ. 2005;173(5):489-95.

45. Freedson PS, Melanson E, Sirard J. Calibration of the computer science and applications, Inc. accelerometer. Med Sci Sports Exerc. 1998;30(5):777-81.

46. Coen RF, Robertson DA, Kenny RA, et al. Strengths and limitations of the MoCA for assessing cognitive functioning findings from a large representative sample of Irish older adults. J Geriatr Psychiatry Neurol. 2016;29(1):18-24.

47. Wechsler D. WAIS-IV UK Administration and scoring manual. London: Pearson; 2010.

48. Reitan RM. Validity of the trail making test as an indicator of organic brain damage. Percep Mot Skills. 1958;8:271-6.

49. Ponton MO. Research and assessment issues with Hispanic populations. In: Neuropsychology and the Hispanic patient: a clinical handbook. Mahwah, NJ: Lawrence Erlbaum Associates; 2001. p. 39-58.

50. Goldberg D, Bridges K, Duncan-Jones P, et al. Detecting anxiety and depression in general medical settings. Br Med J. 1988;297(6653):897-9.

51. de Jong-Gierveld J. Developing and testing a model of loneliness. J Pers Soc Psychol. 1987;53(1):119-28.

52. Logsdon RG, Gibbons LE, McCurry SM, et al. Assessing quality of life in older adults with cognitive impairment. Psychosom Med. 2002;64:510-9.

53. Charlson M, Szatrowski TP, Peterson J, et al. Validation of a combined comorbidity index. J Clin Epidemiol. 1994;47(11):1245-51.

54. Perera S, Mody SH, Woodman RC, et al. Meaningful change and responsiveness in common physical performance measures in older adults. J Am Geriatr Soc. 2006:54(5):743-9.

55. World Health Organization. Regional Committee for Europe $66^{\text {th }}$ Session. Action plan for the prevention and control of noncommunicable diseases in the WHO European Region. Copenhagen, Denmark, 12-15 September 2016. http://www.euro.who.int/ data/assets/pdf file/0011/315398/ 66wd11e_NCDActionPlan_160522.pdf?ua=1.

56. Rezola-Pardo C, Arrieta H, Vidán A, et al. Comparación de un programa de ejercicio físico multicomponente con un programa de ejercicio multicomponente dual (dual-task) en la función física de personas mayores de centros residenciales: datos preliminares del estudio Aging-ONDUAL-TASK. 2018; XVII Congress of Zahartzaroa. 